\title{
Oxygen diffusion in soils: Understanding the factors and processes needed for modeling
}

\author{
José Neira ${ }^{1 *}$, Mauricio Ortiz ${ }^{1}$, Luis Morales ${ }^{2}$, and Edmundo Acevedo ${ }^{2}$
}

\begin{abstract}
Oxygen is an important element for plant growth. Reducing its concentration in the soil affects plant physiological processes such as nutrient and water uptake as well as respiration, the redox potential of soil elements and the activity of microorganisms. The main mechanism of oxygen transport in the soil is by diffusion, a dynamic process greatly influenced by soil physical properties such as texture and structure, conditioning, pore size distribution, tortuosity and connectivity. Organic matter is a modifying agent of the soil's chemical and physical properties, affecting its structure and the porous matrix, which are determinants of oxygen transport. This study reviews the theory of soil gas diffusion and the effect of soil organic matter on the soil's physical properties and transport of gases. It also reviews gas diffusion models, particularly those including the effect of soil organic matter.
\end{abstract}

Key words: Diffusion, diffusion coefficient, Fick’s laws, organic matter, oxygen transport.

\section{INTRODUCTION}

Gas transport in the soil is a phenomenon in which gases move mainly by diffusion. Diffusion is defined as the random movement of particles due to kinetic energy; it may occur in a gaseous or liquid medium, with a net movement of the diffusing substance from a higher to a lower concentration (Hillel, 2003). Gas diffusion is conditioned by the physical properties of the soil, among which soil porosity is one of the most important. Soil porosity is usually divided into the water-filled porosity $(\phi)$ and the air-filled porosity $(\varepsilon)$ (Hillel, 1980), parameters that have shown high correlation with plant production (Dasberg and Bakker, 1970). Larger pores generally allow more rapid movement of gases than smaller pores; thus, more gas diffusion occurs in the soil's macropores (Horn and Smucker, 2005), which are also used for root growth. Therefore, it is expected that macropores will generally be well aerated and have higher oxygen concentrations, while micropores will have a more deficient aeration.

Gases, including oxygen, move in the soil according to diffusion laws. The main parameter related to gas diffusion in soil is the gas diffusion coefficient of the

\footnotetext{
${ }^{1}$ Centro de Estudios Avanzados en Fruticultura (CEAF), Camino Las Parcelas 882, sector Los Choapinos, Rengo, Chile.

*Corresponding author (jneira@ceaf.cl).

${ }^{2}$ Universidad de Chile, Facultad de Ciencias Agronómicas, Santa Rosa 11315, La Pintana, Santiago, Chile.

Received: 14 January 2015.

Accepted: 7 May 2015.
}

doi:10.4067/S0718-58392015000300005 soil $\left(D_{p}\right)$, which is a property of the medium and the gas under study and depends upon the texture, structure, distribution, size and connectivity of the pores as well as their tortuosity (Schjønning et al., 1999; Moldrup et al., 2001). Compaction and water saturation of soils are the main barriers to soil oxygen transport, water being a more effective barrier (Papendick and Runkles, 1965; Moldrup et al., 2000a; Neale et al., 2000). The diffusion of gases in water is slower than their diffusion in air by a factor of $10^{4}$ (Call, 1957; Moldrup et al., 2000a; 2004; Thorbjørn et al., 2008).

The oxygen present in the atmosphere of the soil is used in different processes and may be limited by flooding or by soil compaction, affecting plant growth (Hillel, 2003; Lal and Shukla, 2004). There are three conditions that relate soil oxygen concentration to plants. In normoxia (normal conditions) respiration is aerobic, metabolism proceeds normally and most ATP is produced by oxidative phosphorylation. Under hypoxia oxygen concentration begins to be limiting for ATP production by the oxidative phosphorylation pathway; while under anoxia ATP is generated by glycolysis since no oxygen is available (Saglio et al., 1988; Horchani et al., 2011).

The effects of oxygen deficiency in the soil may be either direct or indirect; direct effects deal with the lack of oxygen for plant processes, while indirect effects are related to the physical and chemical properties of the soil that use oxygen (Lal and Shukla, 2004). Direct effects restrict processes such as plant respiration, water and nutrient absorption; they produce a change in root metabolism towards fermentation. A critical and limiting value of soil oxygen diffusion for crops is variable and 
is called the oxygen diffusion rate or ODR (Glinski and Stępniewski, 1985), which refers to the availability of oxygen for plants. It has been found that soil oxygen diffusion rates below $20 \times 10^{-8} \mathrm{~g} \mathrm{O}_{2} \mathrm{~cm}^{-2} \mathrm{~min}^{-1}$ do not permit plant emergence (Stolzy and Latey, 1964; Lal and Shukla, 2004). However, plants have the capability to adapt to a deficiency of oxygen in the soil by mechanisms such as developing aerenchyma or by hormonal adjustment (Armstrong et al., 1994).

Indirect effects are produced when anaerobic conditions in soil produce denitrification and reductions in some elements such as Mn, Fe, and sulfate; indirect effects may be divided into chemical and biological. At the chemical level, organic compounds from the decomposition of organic matter, such as ethylene, phenolic acids and acetic acid are produced, which are toxic to plants (Hillel, 2003; Lal and Shukla, 2004); low oxygen concentration also increases the solubility of calcium carbonate, affecting the solubility of $\mathrm{Fe}$ and inducing ferric chlorosis in trees. Manganese is also reduced in soils with poor aeration; when the reduced form accumulates it generates toxic conditions for plants (Taylor and Ashcroft, 1972). At the biological level a decrease in oxygen produces anaerobic decomposition of soil organic matter (SOM), facilitating, for example, the generation of ammonia from protein decomposition instead of forming nitrates as would occur under normal conditions (Taylor and Ashcroft, 1972; Lal and Shukla, 2004).
The aim of this chapter is to discuss the theory of gas diffusion, oriented in oxygen movement, and the soil properties that affect the movement of oxygen in soil.

\section{THEORY OF GAS DIFFUSION IN THE SOIL}

Molecular gas diffusion in soils is controlled by the concentration gradient and the diffusion coefficient. Mathematically, the movement of any gas in the soil under steady state conditions occurs according to the following differential equation, which is Fick's first law:

$$
J=\frac{Q}{A t}=D_{p} \frac{\partial c}{\partial x}
$$

where $J$ is the flux of a given gas, $Q$ is the mass $(\mathrm{g}), A$ is the area $\left(\mathrm{m}^{2}\right), t$ is time, $D_{p}$ is the diffusion coefficient of the gas in the soil, $c$ is the concentration of the gas $\left(\mathrm{g} \mathrm{m}^{-3}\right)$ and $\mathrm{x}$ is the distance. The processes that occur in the soil are more complex than those considered by Fick's First Law, since the flux of a gas in the soil varies over time; that is, gas transport does not occur under steady state conditions (Figure 1). Thus, the movement of oxygen in the soil is described by an equation applicable to transient conditions which also considers oxygen sources and sinks:

$$
\frac{\partial c}{\partial t}=D_{p} \frac{\partial^{2} c}{\partial x^{2}}-S_{g}(S x, t)
$$

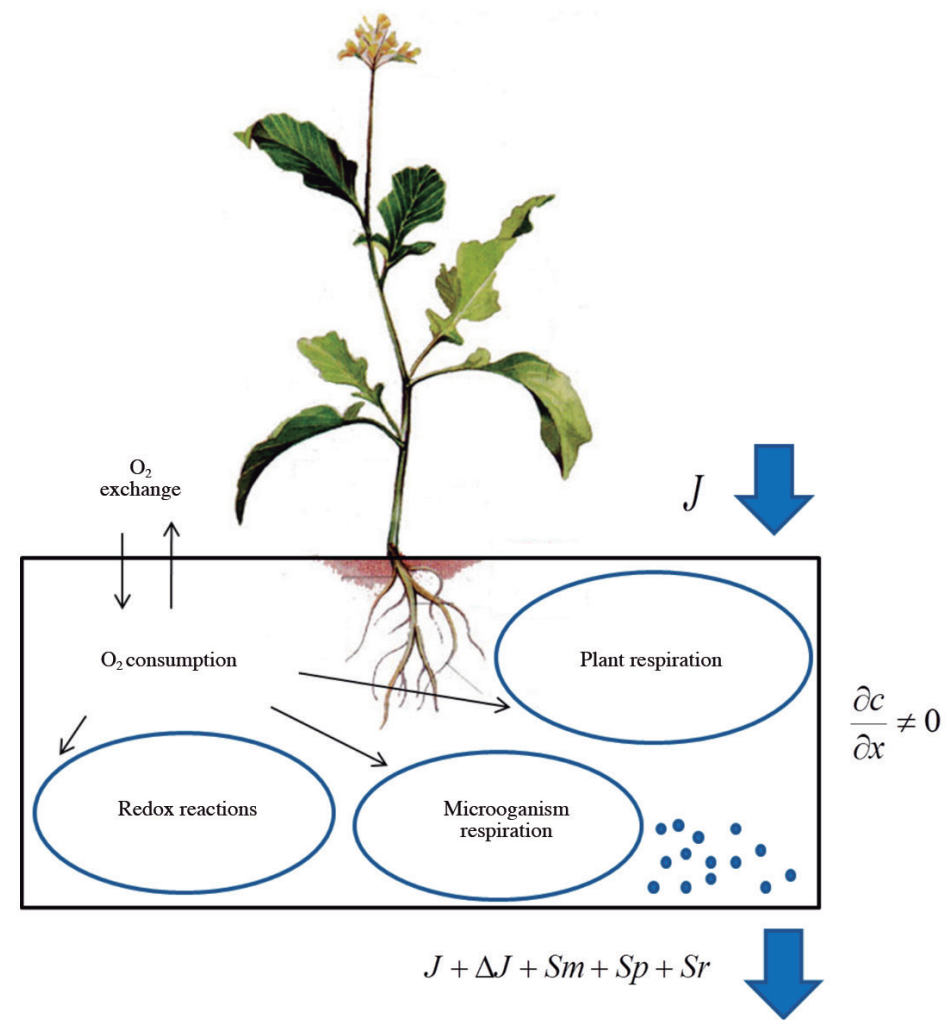

Figure 1. Scheme of soil oxygen dynamics. $J$ is gas density flux, $c$ is gas concentration $\left(\mathrm{g} \mathrm{m}^{-3}\right), t$ is time, $x$ is distance, $S m$ is microorganism respiration, $S p$ is plant respiration, and $S r$ is redox reactions in the soil. 
where $\mathrm{c}$ is gas concentration, $\mathrm{t}$ is time, $\mathrm{x}$ is distance and $S_{g}$ represents the consumption and/or evolution of oxygen due to different sources (microorganisms, roots, oxidation-reduction processes) and depends upon time and distance. Equation [2] has the following assumptions: (1) Diffusion is the only mechanism for oxygen transport; convection is insignificant; and (2) macroscopic diffusion occurs in only one dimension.

The soil gas diffusion coefficient $D_{p}$ incorporates the effects of soil tortuosity and porosity; it is usually estimated by the following equation:

$$
D_{p}=D_{0} \tau \varepsilon
$$

where $D_{0}$ is the diffusion coefficient of the gas in air $\left(\mathrm{m}^{2}\right.$ $\left.\mathrm{s}^{-1}\right), \varepsilon$ is the soil air-filled porosity $\left(\mathrm{m}^{3}\right.$ air $\mathrm{m}^{-3}$ soil) and $\tau$ is the tortuosity of the soil. The soil porosity filled with air $(\varepsilon)$ is a factor essentially controlled by the water-filled porosity $(\phi)$ and the total porosity $(\Phi)$, which depend upon the soil type, organic matter, and management. The total soil porosity is mainly dependent on the texture and structure of the soil.

\section{EFFECT OF SOIL TEXTURE AND STRUCTURE ON GAS TRANSPORT}

The texture of a soil reflects the distribution of particle sizes; it is characterized in size ranges known as textural fractions (sand, silt, and clay), whose combination (soil texture) constitutes the soil matrix (Hillel, 2003), the spatial heterogeneity of texture distribution in the different components or properties of the soil (Dexter, 1988). The spatial variability in the ordering of soil particles affects soil physical parameters such as total porosity, porosity with air, water retention, tortuosity of the pore system, and fractures that allow preferential flow in the soil; these are all factors affecting diffusion of gases in soil (Buckingham, 1904; Penman, 1940; Millington and Quirk, 1961; Troeh et al., 1982; Hamamoto et al., 2009). The pore matrix of soil aggregates includes large pores $>50 \mu \mathrm{m}$ across and small pores $<2 \mu \mathrm{m}$ in diameter, which results in a heterogeneous pore system that affects transport (Horn and Smucker, 2005).

Modification of the soil structure due to compaction limits gas transport in the soil, since it decreases the pore spaces filled with air where gas diffusion occurs (Czyz, 2004; Fujikawa and Miyazaki, 2005). Soil compaction due to the movement of agricultural machinery increases the soil's bulk density, and oxygen diffusion rates may decrease to levels unfavorable for plant growth (Czyz and Tomaszewska, 1993; Dexter and Czyz, 2000; Horn et al., 2000; Czyz, 2004).

The permeability of a soil to air, which is the coefficient that controls the transmission of air through the soil by convection in response to a pressure gradient (Czyz and Tomaszewska, 1993), is a property of the porous medium that is strongly related to total porosity, pore size distribution, continuity and tortuosity of the porous system; thus, this soil property is sensitive to structural changes (Bear, 1972; Dorner and Dec, 2007). Higher values of soil permeability to air have been found in structured compared to unstructured soils (McCarthy and Brown, 1992); thus, it is expected that soils with greater air permeability will have larger gas diffusion coefficients (Horn and Smucker, 2005).

The soil oxygen diffusion is limited by two resistance factors related to soil structure and texture; the first is related to the blocking effect of water $(w)$, indirectly related to soil porosity, and the second is the effect of soil structural shape $(p)$, directly related to soil particle size and tortuosity (Thorbjørn et al., 2008). Assuming that the soil pores are dry parallel tubes the two factors do not limit oxygen diffusion and we can assume the oxygen flux as free (Figure 2a). However, if we consider other soil structural shapes, plus different water contents (Figures $2 \mathrm{~b}-2 \mathrm{c}$ ), a greater effect of $p$ or $w$ will be observed than in the simpler condition (Figure $2 \mathrm{a}$ ).

\section{Effect of SOM on the soil structure and on the soil oxygen diffusion}

The soil structure is the most important soil property related to oxygen diffusion in the soil, since oxygen diffuses through the pore matrix. Changes in soil structure will have a negative impact on oxygen transport if pore connectivity is decreased or positive if pore connectivity improves. Some effects of OM on soil structure are known (Dexter, 2004; Ellies, 2004; Six et al., 2004; Ellies et al., 2005; Grosbellet et al., 2011) but there is not much information about the effect of SOM on gas diffusion (Resurreccion et al., 2007), although effects of SOM on soil characteristics important for oxygen diffusion, such as the stability of aggregates and the pore matrix, have been reported (Dexter, 2004; Ellies, 2004; Six et al., 2004; Ellies et al., 2005; Grosbellet et al., 2011; Hamamoto et al., 2012; Uteau et al., 2013).

The actions of diverse microorganisms such as bacteria, protozoa, fungi, and others allow the degradation of SOM; especially important are the actions of rhizosphere bacteria and fungi that generate adhesive networks of mycelia or hyphae that are added to the soil particles. Microorganisms unite aggregates by physical unions or by cementing particles. Organic agents such as polysaccharides, hemicelluloses, and other polymers act as cementing agents for particles of sand, silt and clay, originating micro and macroaggregates by attractive forces such as hydrogen bonds and the van der Waals force (Hillel, 2003); thus, the stability and size of soil aggregates depend mostly on the quantities and types of organic materials present. However, it must be considered that: (a) only a portion of the SOM is responsible for the stability of aggregates in water; (b) there is a limiting OM above which the stability of aggregates in water does not increase further, and (c) materials of organic origin are not the most important cementing agents (Tisdall and Oades, 1982). 
(a)

PARALLEL

STRAIGHT TUBES (b)

CoARSE

PARTICLES
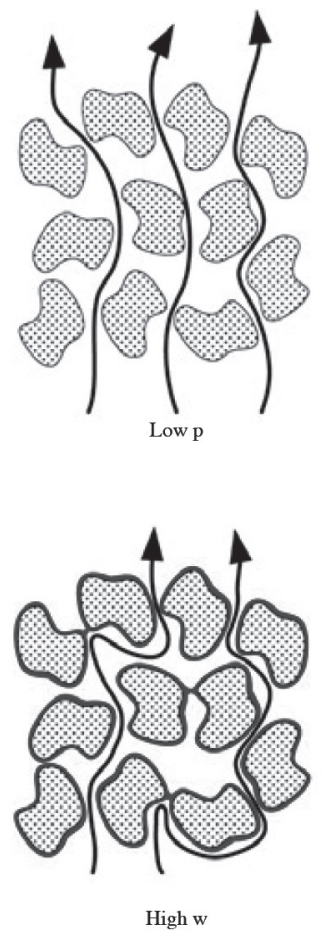

High w (c)

FINE

PARTICLES
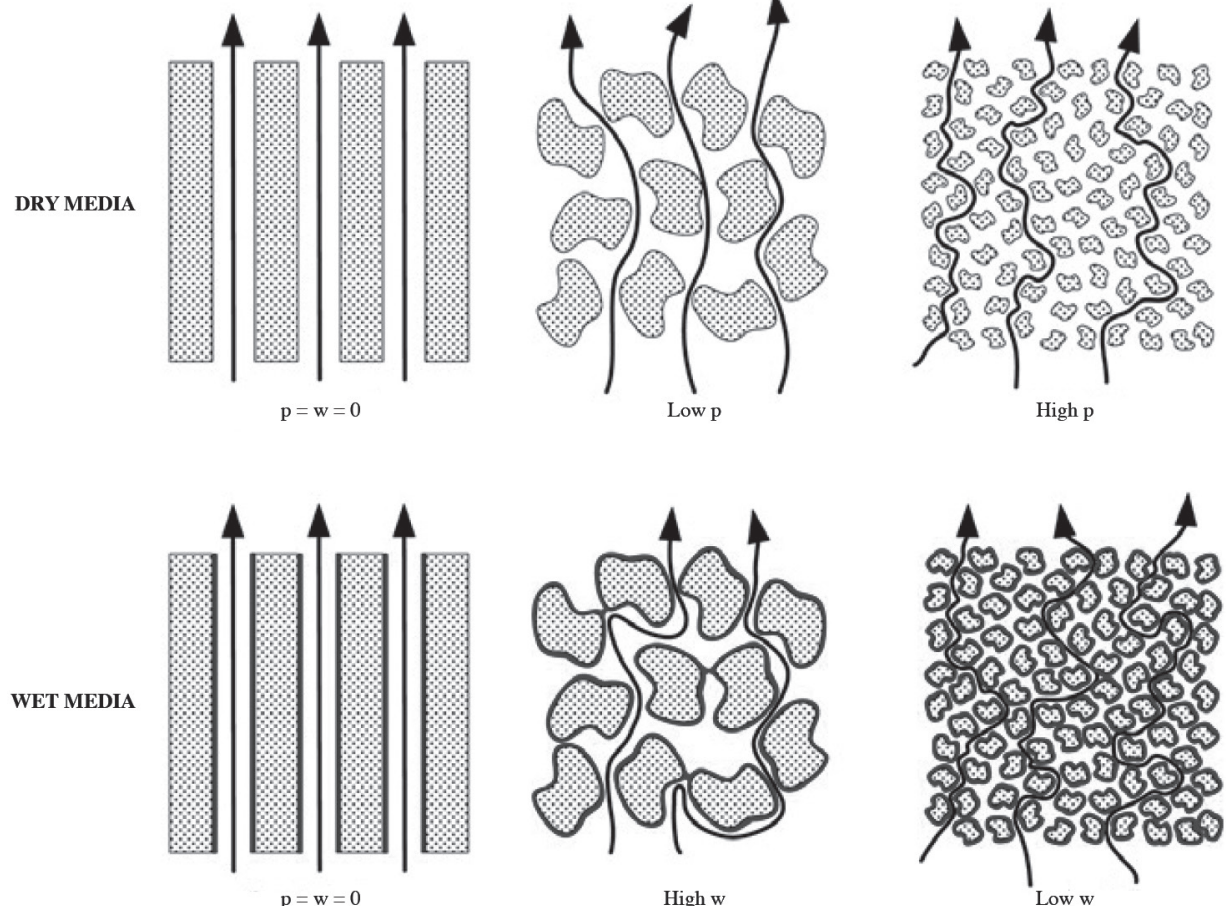

Source: Thorbjørn et al. (2008).

Figure 2. Gas diffusion in parallel straight tubes (a), coarse particles (b), and fine particles (c). The presence of single particles and the addition of water enhance the tortuosity and reduce the connectivity of the gas phase compared with straight parallel tubes, with the texture governing the resistance of the particles (reflected by the particle shape factor $p$ ) and the resistance of the water (reflected by the water-blockage factor $w$ ), respectively.

There is a positive relation between SOM content and the stability of aggregates (Figure 3). The increased stability of aggregates reduces the tendency of the soil

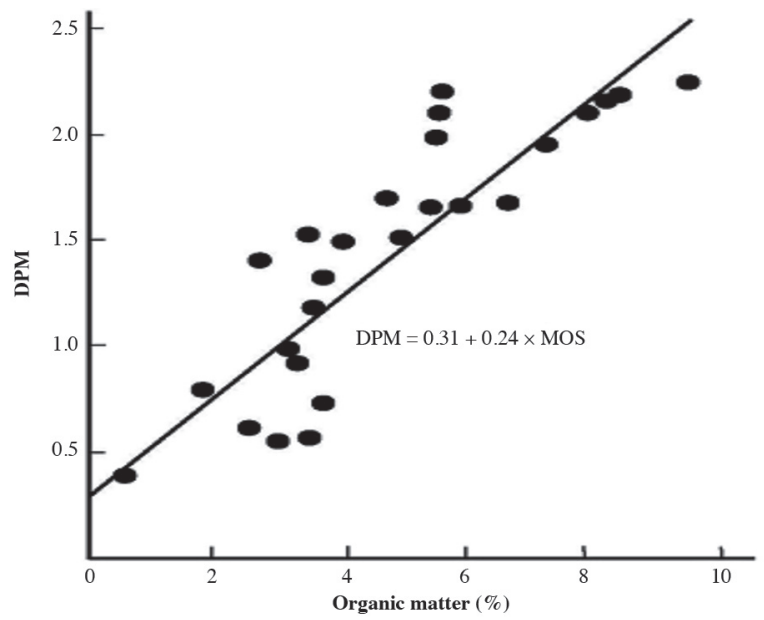

Source: Chaney and Swift (1984) modified by Martínez et al. (2008).

Figure 3. Relation between weighted average diameter (DPM) and soil organic matter (\% SOM) of 26 British soils. to compact and increases its resistance to deformation (Bayhan et al., 2005); it decreases the sensitivity to surface sealing even when the added organic material is less than $10 \mathrm{~g} \mathrm{C} \mathrm{kg}^{-1}$ dry soil (Annabi, 2005; Grosbellet et al., 2011), which is equivalent to $260 \mathrm{~kg} \mathrm{SOM} \mathrm{ha}^{-1}$, if we assume 1 ha of soil $20 \mathrm{~cm}$ deep with a bulk density of 1.3 $\mathrm{g} \mathrm{cm}^{-3}$. Therefore, SOM is important for the formation of stable aggregates and a pore system that improves aeration (Ellies, 2004; Annabi et al., 2007). Soils with high organic content submitted to cycles of wetting and drying, which promote soil structuring, produce a decrease in the volume of fast drainage pores, pores $>50 \mu \mathrm{m}$, and an increase in useful water pores, which are between 2 and $50 \mu \mathrm{m}$ (Antipa, 2007; Leiva, 2009). This implies a modification of the pore matrix that will affect the diffusion of oxygen.

Grosbellet et al. (2011) suggested the existence of two mechanisms of stabilization of the structure and pore generation in disturbed soils by the incorporation, degradation, and fragmentation of organic matter due to the actions of microorganisms (Figure 4). The first refers to the formation of macroaggregates by the aggregation of soil particles around particulate organic matter (POM), 


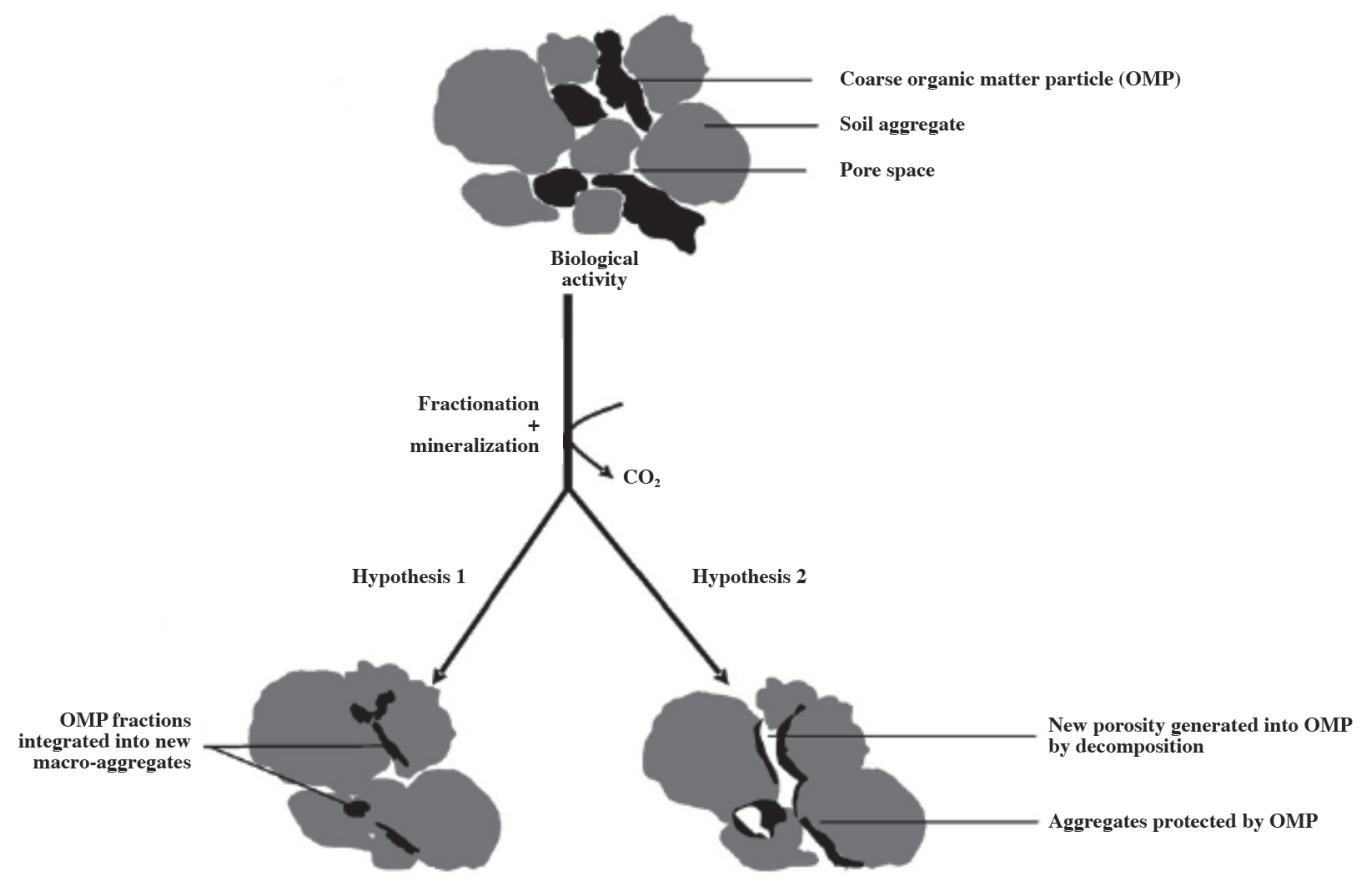

Source: Grosbellet et al. (2011).

Figure 4. Hypotheses 1 and 2 of soil structure formation and management of organic matter particles.

which results in new aggregates; the second mechanism suggests that POM surrounds aggregates present in the soil and that degradation of the $\mathrm{OM}$ generates pores between the soil aggregates. The particulate organic matter corresponds to a labile fraction of the SOM in the soil and is correlated with the mineralization of nitrogen. Hamamoto et al. (2012), on the other hand, observed a reduction in the diffusion coefficient measured in organic soil and associated it with a higher proportion of waterfilled pores that limit diffusion.

\section{Simulation of the oxygen diffusion in the soil}

Soil oxygen diffusion is a complex process. Therefore, to simplify its understanding, it is convenient to separate a macromodel (Figure 5, right), which describes the movement of oxygen between soil surface and root surface through the soil, from a micromodel (Figure 5, left) that describes the movement of oxygen through root cells (Buckingham, 1904; Van Noordwijk and De Willigen, 1984; Bartholomeus et al., 2008). These models have been presented by Campbell (1985), Denison (1992), Cook (1995), Cook and Knight (2003), and Bartholomeus et al. (2008) taking into account different degrees of complexity. The macro and micromodels will be described separately according to Equation [2]. However, due to its importance, gas diffusion coefficient will be treated separately in this work.
Macroscale model of oxygen diffusion. The macroscale model (Figure 5, right) centers on oxygen transport from the atmosphere to the soil up to the gas phase surrounding the root. Root and microorganism respiration are the processes which consume soil oxygen. The soil gas diffusivity $\left(D_{p} D_{0}^{-1}\right)$ is the relation between the diffusion coefficient of a gas in the soil $\left(D_{p}\right)$ and its value in bulk air $\left(D_{0}\right)$; it is a measure related to the resistance that porous media offer to diffusion (Schaefer et al., 1995); it controls soil aeration, which depends upon the type of soil and $\varepsilon$. Taking these elements into account and replacing the appropriate values in Equation [2], we obtain:

$$
\frac{\partial O}{\partial t}=D_{\text {soil }} \frac{\partial^{2} O}{\partial x^{2}}-R_{\text {root_tot }}-R_{\text {microbial }}-R E
$$

where $D_{\text {soil }}$ is the oxygen diffusion coefficient in the soil $\left(\mathrm{m}^{2} \mathrm{~s}^{-1}\right), O$ is the macroscale oxygen concentration $\left(\mathrm{g} \mathrm{m}^{-3}\right)$, $t$ is time and $x$ is the distance. $R_{\text {root } t o t}$ is the respiration of roots $\left(\mathrm{kg} \mathrm{O}_{2} \mathrm{~m}^{-3}\right.$ soil s$\left.{ }^{-1}\right), R_{\text {microbial }}$ is the microbial respiration per soil volume $\left(\mathrm{kg} \mathrm{O}_{2} \mathrm{~m}^{-3}\right.$ soil s $\left.\mathrm{s}^{-1}\right)$ and $R E$ represents the oxidation-reduction reactions in the soil. The functions $R_{\text {root_tot }}$ and $R_{\text {microbial }}$ are described below in the microscale model.

Microscale model of oxygen diffusion. The microscale model (Figure 5, left) centers on the minimum oxygen concentration in the gas phase required by the roots. Two oxygen consumption processes in the root zone depend on temperature: root respiration and microbial respiration in the water-film around the roots; this film is a barrier to 


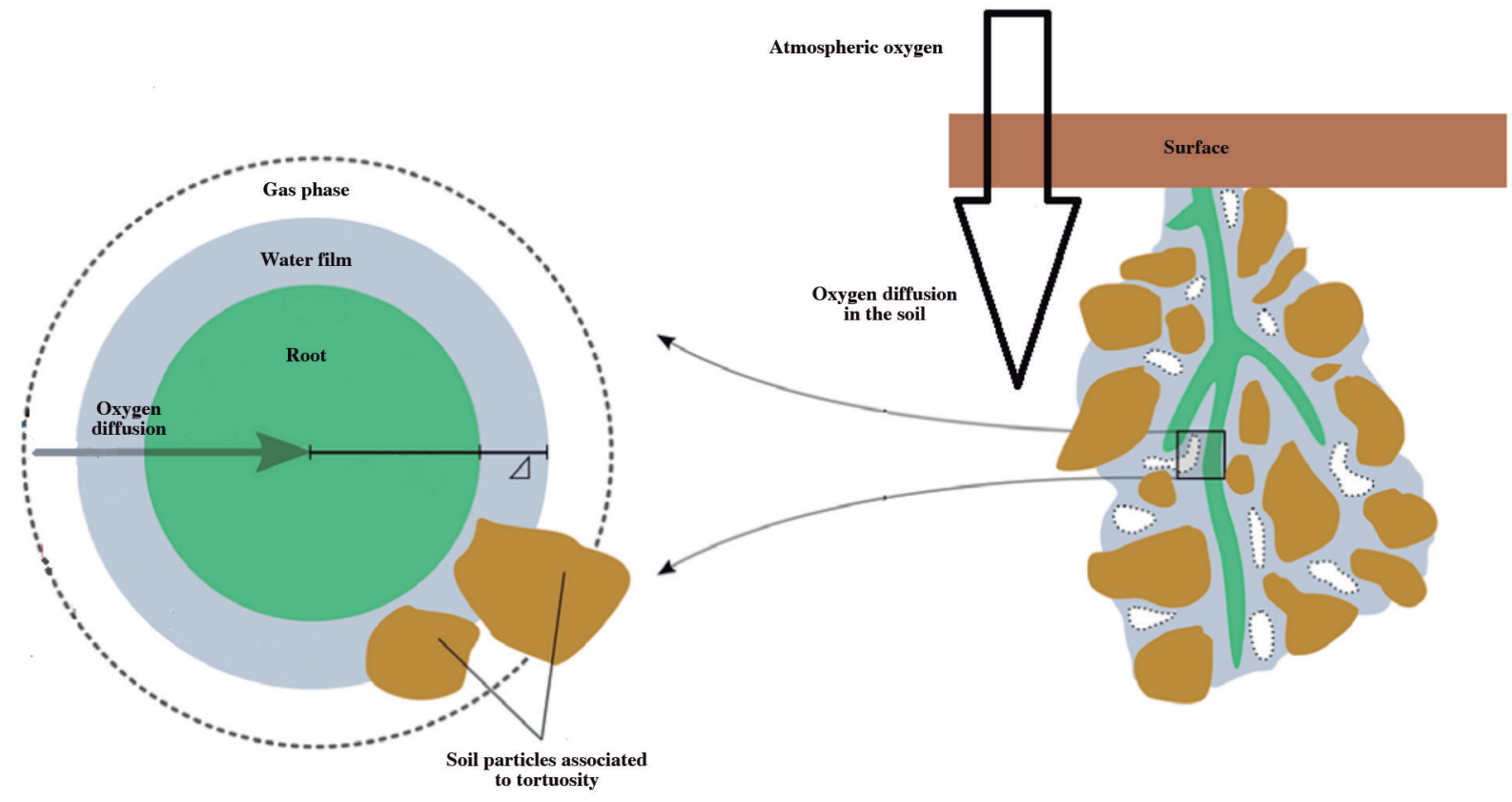

Source: Edited from Bartholomeus et al. (2008).

Figure 5. Scheme of oxygen transport divided into a micromodel on the left side of the figure and a macromodel on the right side of the figure.

oxygen transport. Based on Equation [1], the microscale should be as follows:

$$
\frac{\partial o}{\partial t}=d_{\text {soil }} \frac{\partial^{2} o}{\partial x^{2}}-r_{\text {root_tot }}-r_{\text {microbial }}
$$

where $d_{\text {soil }}$ is the diffusion of oxygen in the waterfilm $\left(\mathrm{m}^{2} \mathrm{~s}^{-1}\right), O$ is the oxygen concentration at the microscale $\left(\mathrm{g} \mathrm{m}^{-3}\right), t$ is time and $x$ is the distance, $r_{\text {root to } t}$ is the respiration of a cylindrical $\operatorname{root}\left(\mathrm{kg} \mathrm{O}_{2} \mathrm{~m}^{-1} \operatorname{root~s}{ }^{-1}\right)$ and $r_{\text {microbial }}$ is the microbial respiration in the water-film $\left.\left(\mathrm{kg} \mathrm{O}_{2} \mathrm{~m}^{-1} \text { root s}\right)^{-1}\right)$.

Root respiration. The equations to calculate root respiration are based on the paradigm of growth and maintenance respiration of plants (Amthor, 2000). The equations below are valid for both the macro and micro scales:

$$
R_{\text {root_tot }}=R_{\text {root_tot_Z0 }} \cdot e^{\left(\frac{-Z}{\left(Z_{\text {root }}\right.}\right)}
$$

where it is assumed that $R_{\text {root_tot }}$ decreases exponentially with depth $\mathrm{z}(\mathrm{m}) ; R_{\text {root_tot_z0 }}$ is the total respiration in superficial roots $\left(\mathrm{kg} \mathrm{O}_{2} \mathrm{~m}^{-3}\right.$ soil s$\left.{ }^{-1}\right)$ and $Z_{\text {root }}$ is a form parameter (Campbell, 1985; Cook, 1995). Equation [7] takes the effect of temperature on root respiration into consideration:

$$
R_{\text {root_tot_Z0 }}=R_{\text {root_tot_Z0_ref }} \cdot Q_{10 \_ \text {root }}^{\left(\frac{T_{\text {soil }}-T_{\text {ref }}}{10}\right)}
$$

where $R_{\text {root_tot_z0_ref }}$ is the total reference respiration at $\mathrm{z}=0$ and $Q_{10 \text {-root }}$ is the relative increase in root respiration with a temperature increase of $10^{\circ} \mathrm{C}$; this parameter is widely accepted as showing the sensitivity of plant physiological processes to temperature changes (Lloyd and Taylor,
1994). $T_{\text {soil }}$ and $T_{\text {ref }}$ correspond to the soil temperature $\left({ }^{\circ} \mathrm{K}\right)$ and reference temperature $\left(298^{\circ} \mathrm{K}\right)$, respectively.

$$
R_{\text {roo_tot_Z0_ref }}=K_{m} \cdot W
$$

where $K_{m}$ corresponds to the coefficient of root maintenance $\left(\mathrm{kg} \mathrm{O}_{2} \mathrm{~kg}^{-1}\right.$ roots s$\left.{ }^{-1}\right)$ and $W$ is the specific mass of roots ( $\mathrm{kg}$ roots $\mathrm{m}^{-1}$ roots).

Respiration of microorganisms. The following are the equations for microorganism respiration at the micro $(r)$ and macro scales $(\mathrm{R})$ :

$$
\begin{aligned}
& R_{\text {microbial }}=R_{\text {microbial_Z0 }} \cdot e^{\left(\frac{-z}{Z_{\text {microbiai }}}\right)} \\
& r_{\text {microbial }}=r_{\text {microbial_zo }} \cdot e^{\left(\frac{-z}{Z_{\text {microbial }}}\right)}
\end{aligned}
$$

where it is assumed that $R_{\text {microbial }}$ decreases exponentially with depth $\mathrm{z}(\mathrm{m}) ; R_{\text {microbial_zo }}$ is microbial respiration at the surface $\left(\mathrm{kg} \mathrm{O}_{2} \mathrm{~m}^{-3}\right.$ soil s $\left.\mathrm{s}^{-1}\right)$ and $z_{\text {microbial }}$ is a form parameter associated with the decrease in resources for microbial respiration at depth $z$ :

$$
\begin{aligned}
& R_{\text {microbial_z0 }}=f_{\Psi} \cdot \mu \cdot \beta \cdot Q_{10 \_ \text {microbial }}^{\left(\frac{T_{\text {soil }}-T_{\text {ref }}}{10}\right)} \\
& r_{\text {microbial_z0 }}=0.5 \cdot(\mu \cdot A) \cdot \beta \cdot Q_{10 \_ \text {microbial }}^{\left(\frac{T_{\text {soil }}-T_{\text {ref }}}{10}\right)}
\end{aligned}
$$

where $f_{\psi}$ is a factor of reduced microbiological activity that depends upon the water content of the soil, $\mu$ is soil organic $\mathrm{C}$ content, $\beta$ is a parameter that depends on the vegetation whose value is $2.258 \pm 1.085 \mathrm{e}^{-4}$ (Fierer et al., 2006), $A$ is the area of the water layer around a transverse section and $Q_{10 \_ \text {microbial }}$ is the relative increase in microbial respiration with a $10{ }^{\circ} \mathrm{C}$ temperature increase (Atlas and Bartha, 1987): 


$$
\mu=0.48\left(\frac{M O}{100}\right) \rho_{\text {soil }}
$$

where $\mu$ is calculated based on the organic matter (SOM) content and the soil density $\left(\rho_{\text {soil }}\right)$. It is assumed that $f_{\psi}$ decreases linearly with the logarithm of the matrix potential $(\psi)$ in the range: $\psi 1(-25 \mathrm{kPa}), \psi 2(-762.5 \mathrm{kPa})$, $\psi 3(-1.500 \mathrm{kPa}) ; \psi s a t$ is the saturation matrix potential.

$$
f_{\Psi}\left[\begin{array}{lll}
0.5 & \Psi<\Psi_{\text {sat }} \\
1.0 & -0.5 \frac{\log (\Psi 1)-\log (\Psi)}{\log (\Psi 1)-\log \left(\Psi_{\text {Sat }}\right)} & \Psi_{\text {sat }}<\Psi<\Psi 1 \\
1.0 & \Psi 1<\Psi<\Psi 2 \\
1.0-\frac{\log \Psi-\log (\Psi 2)}{\log (\Psi 3)-\log (\Psi 2)} & \Psi 2<\Psi<\Psi 3 \\
0.0 & \Psi<\Psi 3
\end{array}\right.
$$

Gas diffusion coefficient in the soil. The diffusion coefficient is the most important parameter in the equation of gas diffusion in the soil; a number of empirical and semi-empirical relations have been developed to estimate it based on physical soil parameters or soil water content. These relations were classified by Moldrup et al. (2000b; 2004) into 6 groups, of which the first three are the most important: (1) The first group consists of models of $D_{p}$ based on $\varepsilon$. It was suggested that the relative diffusion coefficient in soils is proportional to $\varepsilon^{2}$ (Buckingham, 1904). Other classical models are the linear diffusion models developed by Penman (Equation [14], Penman, 1940), van Bavel (1952) and Call (1957), as well as the nonlinear models of Marshall (Equation [15], Marshall, 1959), and Millington (Equation [16], Millington, 1959); the last two may be considered mechanistic models (Ball et al., 1988, Collin and Rasmuson, 1988):

$$
\begin{gathered}
D_{p}=0.66 \cdot D_{0} \cdot \varepsilon \\
D_{p}=D_{0} \cdot \varepsilon^{\frac{3}{2}} \\
D_{p}=D_{0} \cdot \varepsilon^{\frac{4}{3}}
\end{gathered}
$$

(2) The second group is composed of empirical, nonlinear or mechanistic models that take into account both $\varepsilon$ and the total soil porosity $(\Phi)$. These models include a minor effect of the type of soil with $\Phi$, since this parameter depends upon the conditions or characteristics of the soil. The most utilized model in this category is the one developed by Millington and Quirk (Equation [17], Millington and Quirk, 1960), which was later improved in 1961 (Equation [18], Millington and Quirk, 1961) and 1996 (Jin and Jury, 1996b), though this model has never been validated against gas diffusivity data for undisturbed soils representing a broad range of soil types and porosities:

$$
\begin{aligned}
& D_{p}=D_{0} \frac{\varepsilon^{2}}{\Phi^{\frac{2}{3}}} \\
& D_{p}=D_{0} \frac{\varepsilon^{\frac{10}{3}}}{\Phi^{2}}
\end{aligned}
$$

(3) The third group use the soil water retention curve (SWC) as additional information to estimate gas diffusion, introducing a parameter $b$ (Campbell, 1974). This parameter is the slope of the characteristic curve of a $\log (\theta)-\log (\psi)$ system, and has been proposed as an index which describes the effects of heterogeneity at a local scale in the bulk density and $\varepsilon$ (Equation [19], Moldrup et al., 1996; 2001).

$$
D_{p}=D_{0} \Phi^{2}\left[\frac{\varepsilon}{\Phi}\right]^{2+\frac{3}{b}}
$$

Groups 4, 5, and 6 are descriptive models which serve mainly to understand the movement of gases in the soil (Ball, 1981; Nielson et al., 1984; Arah and Ball, 1994; Steele and Nieber, 1994) in which the large number of empirical constants that must be fit limits their application for the prediction of gas diffusion in the soil (Freijer, 1994).

The diffusion coefficients in the first three groups were developed in samples of altered, screened, and/or restructured soils, which limit their application under field or natural situations. The inclusion of the $b$ parameter in group 3 has provided a better fit to the data of the results obtained by modeling.

Problems for the estimation of the soil oxygen content The models of soil gas diffusion are adaptations of models developed for non-gaseous fluids (Ho and Webb, 2006). Most of the models used were developed through the study of gas diffusion in altered and restructured soil samples (Kristensen et al., 2010), such as the diffusion coefficients of groups 1 and 2, which renders these models not very useful in predicting oxygen content in field situations, since they underestimate gas diffusion under these conditions (Petersen et al., 1994; Jin and Jury, 1996a; Bartelt-Hunt and Smith, 2002; Werner et al., 2004). The first mathematical approximations of soil gas diffusion used the equations of Fick's laws, which assume that the porous medium in which gas is transported is homogeneous (Obando, 2003); this departs from the real situation of soils in which the texture and structure of the porous media have heterogeneous characteristics (Obando, 2003). Currie (1965) emphasized the limitations of approximations using Fick's equations due to differences in the porous system between natural and cultivated soils, in which the preferential zones through which gases and liquids are transported are different for soil aggregates or clods, the porous media being different for each situation. Another limitation shown by Currie (1965) is that the porous structure of soils has a bimodal character and gas transport occurs in porous media having two groups of pores with different characteristics (Currie, 1965); thus, the parameters $\varepsilon$ and $\Phi$ used in the diffusion models may be considered insufficient to describe the characteristics of the pore matrix (Liu et al., 2006).

In spite of the limitations of Fick's laws they are the most common and simple approximation to soil gas diffusion, and have been fit to diverse situations by introducing factors related to the characteristics of the pore matrix, where can be written in a general form proposed by Moldrup et al. (2013): 


$$
\frac{D_{p}}{D_{0}}=P \varepsilon^{x}\left[\frac{\varepsilon}{\Phi}\right]^{T_{a}}
$$

where $D_{p}$ is the gas diffusion coefficient in soil $\left(\mathrm{cm}^{3}\right.$ air $\mathrm{cm}^{-1}$ soil s $\left.\mathrm{s}^{-1}\right), D_{0}$ is the gas diffusion coefficient in free air $\left.\left(\mathrm{cm}^{2} \text { air s}\right)^{-1}\right), \varepsilon$ is the soil-air content $\left(\mathrm{cm}^{3}\right.$ soil-air $\mathrm{cm}^{-3}$ soil), $\Phi$ is total soil porosity $\left(\mathrm{cm}^{3}\right.$ soil pore space $\mathrm{cm}^{-3}$ soil), and $P, X$, and $T_{\mathrm{a}}$ are model parameters.

SOM has an important effect on the soil pore matrix, the stability of the aggregates and the tortuosity-connectivity of the pores due to disaggregation of the soil particles or pore size distribution. Hamamoto et al. (2012) described a model that includes the effect of organic matter on the gas diffusion coefficient and is written as follows:

$$
\frac{D_{p}}{D_{0}}=\left(\varepsilon-\varepsilon_{t h}\right)^{x}
$$

where $\varepsilon_{\mathrm{th}}$ is the percolation threshold $\left(\mathrm{cm}^{3} \mathrm{~cm}^{-3}\right)$ and $\mathrm{X}$ is a porosity-tortuosity factor. Both parameters can be calculated as follows:

$$
\begin{gathered}
\varepsilon_{t h}=0.01 \cdot e^{(2.5 \cdot O M F)} \\
X^{\prime}=1.8+1.4 \cdot O M F
\end{gathered}
$$

This model was developed taking into account a wide range of soil types, for example mineral soils (SOM between $0 \%$ and $13 \%$ ), ash volcanic soils (SOM between $7 \%$ and $20 \%$ ) and organic soils (SOM between $50 \%$ and $85 \%$ ), as different soil textures. Besides this model, Moldrup et al. (2013) developed a model that considers soil structure and is written as follows:

$$
\frac{D_{p}}{D_{0}}=\varepsilon^{[1+c m \Phi]}\left[\frac{\varepsilon}{\Phi}\right]
$$

Both models are simple representations of the general form and have been used to precisely predict soil gas diffusion coefficients under different soil conditions, where they can be used to improve estimations of oxygen diffusion in soil.

\section{CONCLUSIONS}

Oxygen transport in soils occurs mainly by diffusion, a process that depends upon physical characteristics of the soil such as texture, structure, porosity, and water content. These factors affect oxygen transport; organic matter acts positively on some of these physical factors, usually by increasing the aggregate stability and changing the pore size distribution of the soil. These are important factors in gas transport in the soil; however, the effect of organic matter on oxygen diffusion has not been studied directly. There is little information about the effect of organic matter on oxygen diffusion in the soil, and the few studies available have not estimated oxygen accurately.

A number of gas diffusion coefficients in the soil have been derived based on parameters related to its structure and pore system. These parameters should be estimated in studies oriented to determine how organic matter affects gas diffusion, and in consequence soil oxygen transport. One example is in a study developed with different soils and total organic matter contents, the inclusion of a parameter related to the porosity inactive to transport improved the precision of modeling gas diffusion. However, the results obtained cannot be extrapolated to other types of soil without prior testing. A better characterization of the pore system provides the possibility of including the effects of soil organic matter on oxygen transport and thus predicting more precisely its diffusion in soils.

\section{LITERATURE CITED}

Amthor, J. 2000. The McCree-de Wit-Penning de Vries-Thornley respiration paradigms: 30 years later. Annals of Botany 86:1-20.

Annabi, M. 2005. Stabilisation de la structure d'un sol limoneux par des apports de composts d'origine urbaine: relation avec les caractéristiques de leur matière organique. Institut National Agronomique, Paris-Grignon, Paris, France.

Annabi, M., S. Houot, C. Francou, M. Poitrenaud, and Y.L. Bissonnais. 2007. Soil aggregate stability improvement with urban composts of different maturities. Soil Science Society of America Journal 71:413-423.

Antipa, Z. 2007. Efecto de la aplicación de lodos de salmón sobre la estructura de un suelo. Universidad Austral de Chile, Valdivia, Chile.

Arah, J.R.M., and B.C. Ball. 1994. A functional model of soil porosity used to interpret measurements of gas diffusion. European Journal of Soil Science 45:135-144.

Armstrong, W., R. Bräendle, and M. Jackson. 1994. Mechanisms of flood tolerance in plants. Acta Botanica Neerlandica 43:307-358.

Atlas, R.M., and R. Bartha. 1987. Microbial ecology: Fundamentals and applications. The Benjamim/Cummings Publishing Company Inc., California, USA.

Ball, B.C. 1981. Modelling of soil pores as tubes using gas permeabilities, gas diffusivities and water release. European Journal of Soil Science 32:465-481.

Ball, B.C., M.F. Sullivan, and R. Hunter. 1988. Gas diffusion, fluid flow and derived pore continuity indices in relation to vehicle traffic and tillage. European Journal of Soil Science 39:327-339.

Bartelt-Hunt, S.L., and J.A. Smith. 2002. Measurement of effective air diffusion coefficients for trichloroethene in undisturbed soil cores. Journal of Contaminant Hydrology 56:193-208.

Bartholomeus, R.P., J.-P.M. Witte, P.M. van Bodegom, J.C. van Dam, and R. Aerts. 2008. Critical soil conditions for oxygen stress to plant roots: Substituting the Feddes-function by a process-based model. Journal of Hydrology 360:147-165.

Bayhan, A.K., A. Ali Isildar, and M. Akgül. 2005. Tillage impacts on aggregate stability and crop productivity in a loam soil of a dryland in Turkey. Acta Agriculturae Scandinavica, Section B Soil \& Plant Science 55:214-220.

Bear, J. 1972. Dynamics of fluids in porous media. Elsevier, New York, USA.

Buckingham, E. 1904. Contributions to our knowledge of the aeration of soils. USDA, Washington D.C., USA.

Call, F. 1957. Soil fumigation. V. Diffusion of ethylene dibromide through soils. Journal of the Science of Food and Agriculture 8:143-150.

Campbell, G. 1974. A Simple method for determining unsaturated conductivity from moisture retention data. Soil Science 117:311-314.

Campbell, G. 1985. Soil physics with BASIC - Transport models for soil-plant systems. Elsevier, New York, USA.

Collin, M., and A. Rasmuson. 1988. A comparison of gas diffusivity models for unsaturated porous media. Soil Science Society of America Journal 52:1559-1565.

Cook, F.J. 1995. One-dimensional oxygen diffusion into soil with exponential respiration: analytical and numerical solutions. Ecological Modelling 78:277-283. 
Cook, F., and J. Knight. 2003. Oxygen transport to plant roots: Modeling for physical understanding of soil aeration. Soil Science Society of America Journal 67:20-31.

Currie, J.A. 1965. Diffusion within soil microstructure a structural parameter for soils. Journal of Soil Science 16:279-289.

Czyz, E.A. 2004. Effects of traffic on soil aeration, bulk density and growth of spring barley. Soil and Tillage Research 79:153-166.

Czyz, E.A., and J. Tomaszewska. 1993. Changes of aeration conditions and the yield of sugar beet on sandy soil of different density. Polish Journal of Soil Science 9:1-9.

Chaney, K., and R.S. Swift. 1984. The influence of organic matter on aggregate stability in some British soils. Journal of Soil Science $35: 223-230$.

Dasberg, S., and J.W. Bakker. 1970. Characterizing soil aeration under changing soil moisture conditions for bean growth. Agronomy Journal 62:689-692.

Denison, R. 1992. Mathematical modeling of oxygen diffusion and respiration in legume root nodules. Plant Physiology 98:901-907.

Dexter, A.R. 1988. Advances in characterization of soil structure. Soil and Tillage Research 11:199-238.

Dexter, A. 2004. Soil physical quality. Part I. Theory, effects of soil texture, density, and organic matter, and effects on root growth. Geoderma 120:201-214.

Dexter,A., and E.A. Czyz. 2000. Soil physical quality and the effects of management. p. 153-165. In Wilson, M.J., and B. MaliszewskaKordybach (eds.) Soil quality, sustainable agriculture and environmental security. Kluwer, Dordrecht, The Netherlands.

Dorner, J., y D. Dec. 2007. La permeabilidad del aire y conductividad hidráulica saturada como herramienta para la caracterización funcional de poros del suelo. Revista de la Ciencia del Suelo y Nutrición Vegetal 7:1-13.

Ellies, A. 2004. Efecto de la materia orgánica en el suelo. p. 139-150. In M. Mora (ed.) Simposio de la Sociedad Chilena de la Ciencia del Suelo, Temuco. Universidad de la Frontera, Temuco, Chile

Ellies, A., C. Ramírez, and R. Mac Donald. 2005. Organic matter and wetting capacity distribution in aggregates of Chilean soils. CATENA 59:69-78.

Fierer, N., B.P. Colman, J.P. Schimel, and R.B. Jackson. 2006. Predicting the temperature dependence of microbial respiration in soil: A continental-scale analysis. Global Biogeochemical Cycles 20:GB3026.

Freijer, J.I. 1994. Calibration of jointed tube models for the gas diffusion coefficient in soil. Soil Science Society of America Journal 58:1067-1076.

Fujikawa, T., and T. Miyazaki. 2005. Effects of bulk density on the gas diffusion coefficient in repacked and undisturbed soils. Soil Science 170:892-901.

Glinski, J., and W. Stępniewski. 1985. Soil aeration and its role for plants. CRC Press, Boca Raton, Florida, USA.

Grosbellet, C., L. Vidal-Beaudet, V. Caubel, and S. Charpentier. 2011. Improvement of soil structure formation by degradation of coarse organic matter. Geoderma 162:27-38.

Hamamoto, S., P. Moldrup, K. Kawamoto, and T. Komatsu. 2009. Effect of particle size and soil compaction on gas transport parameters in variably saturated, sandy soils. Vadose Zone Journal 8:986.

Hamamoto, S., P. Moldrup, K. Kawamoto, and T. Komatsu. 2012. Organic matter fraction dependent model for predicting the gas diffusion coefficient in variably saturated soils. Vadose Zone Journal 11(1)

Hillel, D. 1980. Fundamental of soil physics. Academic Press, New York, USA.

Hillel, D. 2003. Introduction to Environmental Soil Physics. Elsevier Academic Press, San Diego, California, USA.

Ho, C.K., and S.W. Webb. 2006. Gas transport in porous media. Springer, Dordrecht, The Netherlands.

Horchani, F., O. R`bia, and S. Aschi-Smiti. 2011. Oxygen sensing and plant acclimation to soil flooding. International Journal of Agricultural Research 6:227-237.
Horn, R., J.J.H. van den Akker, and J. Arvidsson. 2000. Subsoil compaction: Distribution, processes and consequences. Advances in GeoEcology 32. 462 p. Catena Verlag GMBH, Reiskirchen, Germany.

Horn, R., and A. Smucker. 2005. Structure formation and its consequences for gas and water transport in unsaturated arable and forest soils. Soil and Tillage Research 82:5-14.

Jin, Y., and W.A. Jury. 1996a. Characterizing the dependence of gas diffusion coefficient on soil properties. Soil Science Society of America Journal 60:66-71.

Jin, Y., and W.A. Jury. 1996b. Methyl bromide diffusion and emission through soil columns under various management techniques. Journal of Environmental Quality 24:1002-1009.

Kristensen, A.H., A. Thorbjørn, M.P. Jensen, M. Pedersen, and P. Moldrup. 2010. Gas-phase diffusivity and tortuosity of structured soils. Journal of Contaminant Hydrology 115:26-33.

Lal, R., and M. Shukla. 2004. Principles of soil physics. Marcel Dekker, New York, USA. European Journal of Soil Science 56:683-684. doi:10.1111/j.1365-2389.2005.0756c.x.

Leiva, C. 2009. Caracterización del monto, funcionalidad y evolución del sistema poroso de un Palehumult al ser sometidos a ciclos de formación de estructura. Universidad Austral de Chile, Valdivia, Chile.

Liu, G., B. Li, K. Hu, and M.T. van Genuchten. 2006. Simulating the gas diffusion coefficient in macropore network images: Influence of soil pore morphology. Soil Science Society of America Journal 70:1252-1261

Lloyd, J., and J.A. Taylor. 1994. On the temperature dependence of soil respiration. Functional Ecology 8:315-323.

Marshall, T.J. 1959. The diffusion of gases through porous media. Journal of Soil Science 10:79-82.

Martínez, E., J. Fuentes, y E. Acevedo. 2008. Carbono orgánico y propiedades del suelo. Revista de la Ciencia del Suelo y Nutrición Vegetal 8:68-96.

McCarthy, K.P., and K.W. Brown. 1992. Soil gas permeability as influenced by soil gas-filled porosity. Soil Science Society of America Journal 57:997-1003.

Millington, R.J. 1959. Gas diffusion in porous media. Science 130:100-102.

Millington, R.J., and J.M. Quirk. 1960. Transport in porous media. p. 97-106. In F.A. van Beren et al. (eds.) $7^{\text {th }}$ Transactions of the International Congress of Soil Science, Madison, Wisconsin. 1424 August Elsevier, Amsterdam, The Netherlands.

Millington, R.J., and J.M. Quirk. 1961. Permeability of porous solids. Transaction of the Faraday Society 57:1200-1207.

Moldrup, P., T.K.K. Chamindu Deepagoda, S. Hamamoto, T. Komatsu, K. Kawamoto, D.E. Rolston, et al. 2013. Structuredependent water-induced linear reduction model for predicting gas diffusivity and tortuosity in repacked and intact soil. Vadose Zone Journal 12:1-11

Moldrup, P., C.W. Kruse, D.E. Rolston, and T. Yamaguchi. 1996. Modeling diffusion and reaction in soils: III.Predicting gas diffusivity from the Campbell soil water retention model. Soil Science 161:366-375.

Moldrup, P., T. Olesen, J. Gamst, P. Schjønning, T. Yamaguchi, and D. Rolston. 2000a. Predicting the gas diffusion coefficient in repacked soil: water-induced linear reduction model. Soil Science Society of America Journal 64:1588-1594.

Moldrup, P., T. Olesen, T. Komatsu, P. Schjønning, and D. Rolston. 2001. Tortuosity, diffusivity, and permeability in the soil liquid and gaseous phases. Soil Science Society of America Journal 65:613-623

Moldrup, P., T. Olesen, P. Schjønning, T. Yamaguchi, and D.E. Rolston. 2000b. Predicting the gas diffusion coefficient in undisturbed soil from soil water characteristics. Soil Science Society of America Journal 64:94-100.

Moldrup, P., T. Olesen, S. Yoshikawa, T. Komatsu, and D. Rolston. 2004. Three-porosity model for predicting the gas diffusion coefficient in undisturbed soil. Soil Science Society of America Journal 68:750-759. 
Neale, N., J. Hughes, and C. Ward. 2000. Impacts of unsatured zone properties on oxygen transport and aquifer reaeration. Ground Water 38:784-794.

Nielson, K.K., V.C. Rogers, and G.W. Gee. 1984. Diffusion of radon through soils. A pore distribution model. Soil Science Society of America Journal 48:482-487.

Obando, F. 2003. Oxygen transport in waterlogged soils. Part II Diffusion coefficients. College on Soil Physics, Trieste. 3-21 March. International Centre for Theoretical Physics, Trieste, Italy.

Papendick, R.I., and J.R. Runkles. 1965. Transient-state oxygen diffusion in soil: I. The case when rate of oxygen consumption is constant. Soil Science 100:251-261.

Penman, H.L. 1940. Gas and vapor movements in soil: The diffusion of vapors through porous solids. Journal of Agricultural Science 30:437-462.

Petersen, L.W., P. Moldrup, D.E. Rolston, and T. Yamaguchi. 1994. Volatile organic vapor diffusion and adsorption in soils. Journal of Environmental Quality 23(4):799-805.

Resurreccion, A.C., K. Kawamoto, T. Komatsu, P. Moldrup, K. Sato, and D.E. Rolston. 2007. Gas diffusivity and air permeability in a volcanic ash soil profile: Effects of organic matter and water retention. Soil Science 172:432-443.

Saglio, P., M. Drew, and A. Pradet. 1988. Metabolic acclimation to anoxia induced by low (2-4 $\mathrm{kPa}$ partial pressure) oxygen pretreatment (hypoxia) in root tips of Zea mays. Plant Physiology 86:61-66.

Schaefer, C.E., H.-A. Arands, H.A. van der Sloot, and D.S. Kosson. 1995. Prediction and experimental validation of liquid-phase diffusion resistance in unsaturated soil. Journal of Contaminant Hydrology 20:145-166.

Schjønning, P., I.K. Thomsen, J.P. Møberg, H. de Jonge, K. Kristensen, and B.T. Christensen. 1999. Turnover of organic matter in differently textured soils: I. Physical characteristics of structurally disturbed and intact soils. Geoderma 89:177-198.
Six, J., H. Bossuyt, S. Degryze, and K. Denef. 2004. A history of research on the link between (micro)aggregates, soil biota, and soil organic matter dynamics. Soil and Tillage Research 79:7-31.

Steele, D.D., and L.L. Nieber. 1994. Network modeling of diffusion coefficients for porous media: I. Theory and model development. Soil Science Society of America Journal 58:1337-1345.

Stolzy, L.H., and J. Latey. 1964. Characterizing soil oxygen conditions with a platinum microelectrode. Advances in Agronomy 16:249-279.

Taylor, S.A., and G.L. Ashcroft. 1972. Physical edaphology: The physics of irrigated and nonirrigated soils. W.H. Freeman, San Francisco, California, USA.

Thorbjørn, A., P. Moldrup, H. Blendstrup, T. Komatsu, and D. Rolston. 2008. A gas diffusivity model based on air-, solid-, and water-phase resistance in variably saturated soil. Vadose Zone Journal 7:1276.

Tisdall, J.M., and J.M. Oades. 1982. Organic matter and water-stable aggregates in soils. Journal of Soil Science 33:141-163.

Troeh, F.R., J.D. Jabro, and D. Kirkham. 1982. Gaseous diffusion equations for porous materials. Geoderma 27:239-253

Uteau, D., S.K. Pagenkemper, S. Peth, and R. Horn. 2013. Root and time dependent soil structure formation and its influence on gas transport in the subsoil. Soil and Tillage Research 132:69-76.

van Bavel, C.H.M. 1952. Gaseous diffusion and porosity in porous media. Soil Science 73:91-104

van Noordwijk, M., and P. De Willigen. 1984. Mathematical models on diffusion of oxygen to and within plant roots, with special emphasis on effects of soil-root contact. I. Derivation of the models. Plant and Soil 77:215-231.

Werner, D., P. Grathwohl, and P. Hohener. 2004. Review of field methods for the determination of the tortuosity and effective gas-phase diffusivity in the vadose zone. Vadose Zone Journal $3: 1240-1248$ 